\title{
Molecular cytogenetic characterization of two murine cancer cell lines derived from salivary gland
}

\section{Ralf Steinacker ${ }^{1}$, Thomas Liehr ${ }^{1}$, Nadezda Kosyakova ${ }^{1}$, Martina Rincic ${ }^{2}$, and Shaymaa S. Hussein Azawi ${ }^{1}$}

1Jena University Hospital, Friedrich Schiller University, Institute of Human Genetics, Am Klinikum 1, D-07747 Jena, Germany

2Department for Functional Genomics, Centre for Translational and Clinical Research, University Hospital Centre Zagreb, University of Zagreb School of Medicine, Zagreb, Croatia

Address correspondence and requests for materials to Thomas Liehr, Thomas.Liehr@med.uni-jena.de

\begin{abstract}
Here two murine salivary gland cancer (SGC) cell lines WR21 and SCA-9 were studied for the first time in detail by high-resolution molecular cytogenetic approaches. This study revealed that these cell lines are models for human SGCs of initial stage myoepithelioid or mucoepidermoid (WR21) and of advanced stage mucoepidermoid (SCA-9) tumors. Besides, three genes most likely playing a role in SGC development (FGF10, ELAVL1/HUR and SEL1) were identified. All of them were involved in translocation events in these in vitro models and thus were most likely activated. Overall, the present study highlights the necessity not only to establish but also to genetically characterize murine tumor cell lines. Without such a characterization they cannot be used in a reasonable way in research.
\end{abstract}

Keywords: salivary gland cancer (SGC), murine tumor cell lines, WR21, SCA-9, myoepithelioid SGC, mucoepidermoid SGC, FGF10, ELAVL1/HUR, SEL1.

\section{Introduction}

Salivary gland cancers (SGCs) are a specific and rare subgroup of tumors known from oral and maxillofacial clinical practice. They account for around 3-5\% of all head and neck cancers and for only less than $0.5 \%$ of all cancers (Zboray et al., 2018). Nevertheless, SGCs include more than 35 histological subtypes and are known for their progressive and heterogeneous clinical behavior (El-Naggar et al., 1997; Persson et al., 2009; Cao et al., 2018).

The mentioned subtypes of SGCs exist partially due to the fact that salivary glands consist of three major paired glands (parotid, submandibular and sublingual) and minor glands, located in the mucosa of the palate, lips and respiratory tract (Omitola and Iyogun, 2018; Zboray et al., 2018). Tumors located in the parotid part are only $25 \%$ malignant. However, the incidence of malignancies is much higher in the submandibular part (50\%) and minor salivary glands (60-80\%) (Sood et al., 2016; Solanki, 2011). In general, SGCs are divided in two forms: (i) a simple palpable lump, being well-defined, discrete, and mobile, and (ii) a lump with significant accompanying symptoms like pain, rapid growth, fixity to surrounding structures, nerve involvement and/or neck metastasis (Sood et al., 2016). Current therapeutic options for human SGCs are limited. Depending on their location, some SGCs can be surgically addressed, while others are difficult to remove completely. Radiation therapy is used; still it has turned out to be less effective for clinical treatment. Accordingly, chemotherapy is the only treatment option in metastatic SGCs (Keller et al., 2017; Zboray et al., 2018).
Citation: Steinacker, R., Liehr, T., Azawi, S. S. 2018. Molecular cytogenetic Author's information: Ralf Steinacke Thomas Liehr, PD, Dr., PhD, Head of Nadezda Kosyakova, MD, PhD, Scientist Martina Rincic, PhD, Scientist; Shaymaa

Manuscript Editor: Alla Krasikova,

Received: October 30, 2018;

Revised: November 22, 2018;

Accepted: December 28, 2018;

Copyright: (c) 2018 Liehr et al. This is an open-access article distributed under the terms of the License Agreement with Sain Petersburg State University, which permits to the authors unrestricted distribution, and self-archiving free of charge.

Funding: This work was supported by Grant No. 2013.032.1 of the Wilhelm Sander-Stiftung.

Competing interests: The authors have declared that no competing interests exist. 
The detailed molecular mechanisms controlling tumor progression and metastasis in SGCs and their genetic profiles are still not well understood (Vekony et al., 2009). However, characterization of these underlying mechanisms is essential for understanding and development of more effective methods of diagnosis and treatment against the disease (Murase et al., 2016). Hence, there is a need for better understanding of the genetics and molecular mechanisms of SGC-pathogenesis, to be used in the future toward the development of novel therapeutic approaches (Cao et al., 2018; Murase et al., 2016; Zboray et al., 2018).

One possible approach for studying the biology of SGCs and developing new therapeutic strategies is the use of mouse models (Zboray et al., 2018). Previous research showed that submandibular gland-derived tumor cell lines present characteristics of differentiated epithelial cells and can be used to study proliferation signaling pathways and their regulation (Trzaskawka et al., 2000; Español et al., 2012). Still, surprisingly, murine cell lines used as models for human SGCs have not yet been very well characterized genetically for their tumor-associated alterations.

Fluorescence in situ hybridization (FISH) and microarray-based comparative genomic hybridization (array CGH) were used in this study to determine the genomic aberrations of the two murine SGC cell lines WR21 and SCA-9. WR21 was first described by Young et al. (2006) as being derived from a salivary tumor in a male wap-ras subline 69-2 (C57BL/6, SJL) transgenic mouse; it was already established in 1989. Such tumors are described as extremely aggressive and as expressing high levels of oncogenic ras-protein from the activated human H-RAS transgene (Nielsen et al., 1994). SCA-9 was already established in 1980 (Barka, 1980; Barka et al., 2005) and was derived from a carcinogen (7,12-dimethylbenz(a)anthracene) -induced tumor of a male Swiss-Webster mouse submandibular gland. Both cell lines have only been applied in 10 published studies (see Pubmed: https://www.ncbi.nlm.nih.gov/ pubmed/?term=wr21 and https://www.ncbi.nlm.nih. gov/pubmed/?term=SCA- $9+$ mouse), which may also be due to the fact that their genetics had not been studied in detail. Here, we analyzed WR 21 and SCA- 9 cell lines by FISH-banding and aCGH and aligned them with their human SGC subtypes.

\section{Material and Methods}

\section{CELL LINES}

The cell lines WR21 and SCA-9 were obtained from American Type Culture Collection (ATCC ${ }^{\circledR}$ CRL-2189 ${ }^{\mathrm{mm}}$, ATCC ${ }^{\oplus}$ CRL-1734 ${ }^{\mathrm{m}}$; Middlesex, UK). They are indicated there as 'not further characterized salivary tumor lines' to be grown adherently in DMEM medium containing $10 \%$ fetal calf serum in the presence of antibiotics. For this study, cells were worked up cytogenetically as previously reported (Rhode et al., 2018) and in parallel whole genomic DNA was extracted using the Blood \& Cell Culture DNA Midi Kit (Qiagen; Hilden, Germany) according to the manufacturer's instructions and described elsewhere (Kubikova et al., 2017). We conducted molecular cytogenetic analyses on the cell line-derived chromosomes and aCGH analyses on the extracted DNA (see below).

According to the ethical committee (medical faculty) and the Animal Experimentation Commission of the Friedrich Schiller University, there are no ethical agreements necessary for studies involving murine tumor cell lines like WR21 and SCA-9.

\section{MOLECULAR CYTOGENETICS}

FISH was performed as previously described (Kubikova et al., 2017). Whole chromosome paints ("SkyPaint ${ }^{\mathrm{TM}}$ DNA Kit M-10 for Mouse Chromosomes", Applied Spectral Imaging, Edingen-Neckarhausen, Germany) were used for multicolor-FISH (mFISH), and murine chromosome-specific multicolor banding $(\mathrm{mcb})$ probe mixes for FISH-banding (Liehr et al., 2006). At least 30 metaphases were documented and analyzed for each probe set ((including using SkyPaint ${ }^{\mathrm{TM}}$ ) Zeiss Axioplan microscopy, equipped with ISIS software (MetaSystems, Altlussheim, Germany)). Array-based comparative genomic hybridization (aCGH) was done according to standard procedures by "SurePrint G3 Mouse CGH Microarray, $4 \times 180 \mathrm{~K}$ " (Agilent Technologies) (Kubikova et al., 2017).

\section{DATA ANALYSIS}

The breakpoints and imbalances of WR21 and SCA-9 were determined after analyses of aCGH and mcb data, and aligned to human homologous regions using Ensembl and the UCSC Genome Browser, as previously described (Leibiger et al., 2013). The obtained data were compared to genetic changes known from human SGCs according to Fowler et al. (2006), Rao et al. (2008), Persson et al. (2009), Vekony et al. (2009), Jee et al. (2013) and Matse et al. (2017).

\section{Results}

WR21 is mitotically relatively stable, and the neardiploid karyotype has an overall low rate of single cell aberrations; still, it developed two main clones. Clone 1 represents $16.6 \%$ of the cells and has the karyotype $44, \mathrm{XY},+\mathrm{Y},+\operatorname{inv}(4)(\mathrm{A} 1 \mathrm{C} 4),+8$, der(9)(A1->E2::E1qter),der(12)(A1->F2::F1->qter),+19. Clone 2 together with one subclone was found in $83.4 \%$ of the cells. Main- 


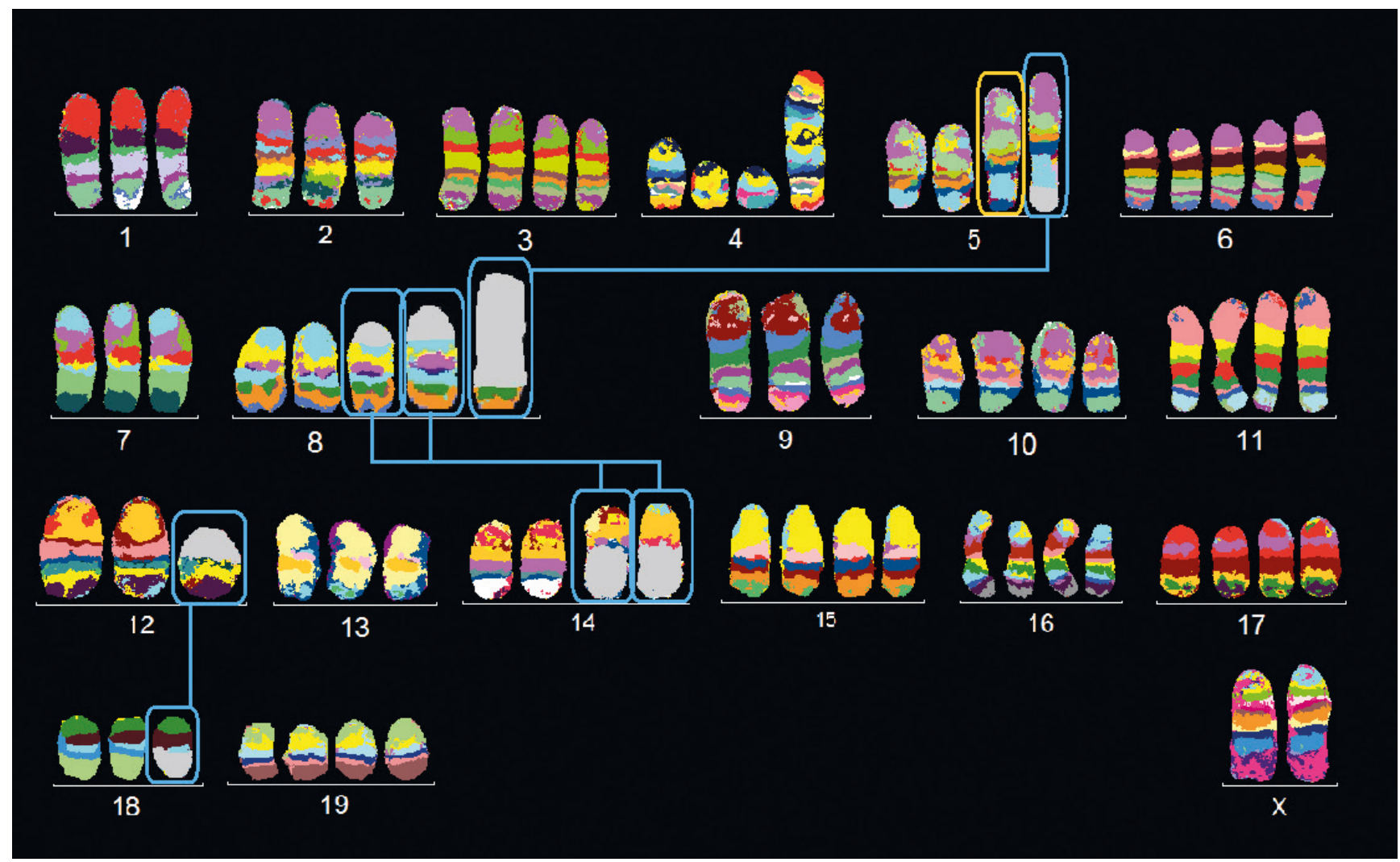

Fig. 1. Murine multicolor banding (mcb) was applied on chromosomes of SGC cell line WR21. Typical pseudocolor banding for all 21 different murine chromosomes is shown for clone 2 . This figure depicts the summary of 21 chromosome-specific FISH-experiments. One derivative chromosome consisting of two different chromosomes is highlighted by frames and shown twice in this summarizing karyogram.

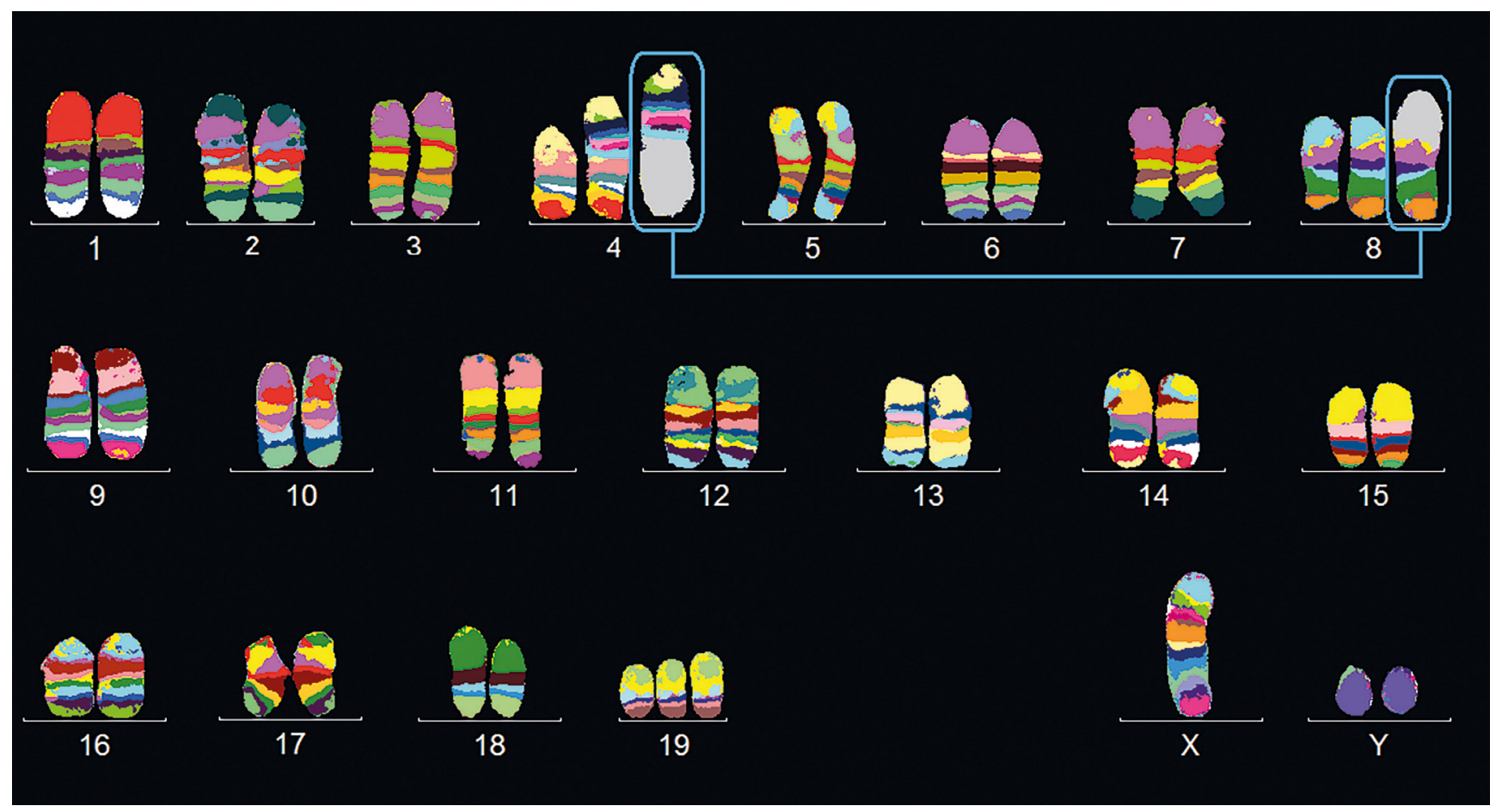

Fig. 2. mcb-results for SGC cell line SCA-9 cell line are shown. Four derivative chromosomes are highlighted by blue frames and shown twice in this summarizing karyogram; the derivative chromosome 5 is highlighted by a yellow frame. 
Table 1. Imbalances larger than one cytoband present in WR21 were translated to their corresponding homologous regions in human karyotype (see Suppl. 1) and are listed in the first column. Those are compared to four common types of human SGCS

\begin{tabular}{|c|c|c|c|c|c|}
\hline Chr. region in human & WR21 & $\begin{array}{c}\text { Adenoid cystic } \\
\text { carcinoma }\end{array}$ & Myoepitheliomas & $\begin{array}{c}\text { pleomorphic } \\
\text { adenoma }\end{array}$ & Mucoepidermoid \\
\hline $11 q 13.3$ & Gain & Gain & & & \\
\hline 19p13.2-p13.12 & Gain & Gain & & & \\
\hline $11 q 12.1-q 13.3$ & Gain & Gain & Gain & & Gain \\
\hline 8p23.3-p21.3 & Gain & & Gain & Loss & Loss \\
\hline 13q33.1-q34 & Gain & & Gain & & Gain \\
\hline $22 q 12.3$ & Gain & & Gain & & \\
\hline 8p12-p11.21 & Gain & & & Gain & \\
\hline $2 q 22.1-q 32.1$ & Loss & & & Gain & \\
\hline 19p13.12-p13.11 & Gain & & & & Gain \\
\hline $3 q 25.1-q 26.2$ & Gain & & & & Gain \\
\hline \multicolumn{2}{|l|}{ Overall agreement } & $3 / 10$ & $4 / 10$ & $1 / 10$ & $4 / 10$ \\
\hline
\end{tabular}

Table 2. Imbalances larger than one cytoband present in SCA-9 were translated to their corresponding homologous regions in human karyotype (see Suppl. 2) and are listed in the first column. Those are compared to 4 human SCG-subtypes

\begin{tabular}{|c|c|c|c|c|c|}
\hline $\begin{array}{c}\text { Chr. region in } \\
\text { human }\end{array}$ & $\begin{array}{l}\text { SCA-9 copy } \\
\text { numbers }\end{array}$ & $\begin{array}{l}\text { Adenoid cystic } \\
\text { carcinoma }\end{array}$ & Myoepitheliomas & $\begin{array}{l}\text { pleomorphic } \\
\text { adenoma }\end{array}$ & Mucoepidermoid \\
\hline $16 p$ & altered & Gain & & & Gain \\
\hline $9 q 33.3-q 34.3$ & altered & Gain & & & \\
\hline $11 q 23.3$ & altered & Gain & & & \\
\hline 19q13.3-p13.11 & altered & Gain & & & Gain \\
\hline $21 q 22.3$ & altered & Gain & & & \\
\hline $13 q 21-q 22$ & altered & Loss & Gain & & Gain \\
\hline 1p32-p36 & altered & Loss & & & Loss \\
\hline $5 q 13.2-q 15$ & altered & & & & Loss \\
\hline $3 p 21.3$ & altered & & & Loss & \\
\hline 11pter-p14.3 & altered & & & Loss & \\
\hline 15q25 qter & altered & & & & Gain \\
\hline $6 p 22 \sim q 24$ & altered & & & & Gain \\
\hline 5pter-p15.31 & altered & & & & Gain \\
\hline $9 q 33.3-q 34.3$ & altered & & & & Gain \\
\hline 18q12.2-qter & altered & & & & Gain \\
\hline $12 \mathrm{p} 13.2$ & altered & & & & Loss \\
\hline \multicolumn{2}{|l|}{ Overall agreement } & $7 / 16$ & $1 / 16$ & $2 / 16$ & $11 / 16$ \\
\hline
\end{tabular}

clone of clone 2 revealed the karyotype $43, \mathrm{XY},+\mathrm{Y}, \mathrm{inv}(4)$ (A1C4),+der(4)t(4;8)(:4C4->4A4::A1-E2),+19 and was present in $77 \%$ of all cells (Fig. 1). In the remaining $6.4 \%$ of the cells, clone 2 further acquired a loss in one of the Y-chromosomes; i.e., there was a $\operatorname{del}(\mathrm{Y})$ - this subset was called clone $2 \mathrm{a}$.
In SCA-9 most chromosomes are tetraploid and the cell line is chromosomally instable, as reflected by many single cell aberrations: 62 76,XX,-1,-2,idic(4)(A1;A1),del(4) (C1), del(4)(C1),der(5)(A1->G3::G3->G2:),der(5)t $(5 ; 8)$ (5A1->5G3::5G3->5G2::8B1->8E2), +6,-7,-8,-8,-9,-12,$12,-13, \operatorname{der}(14) \mathrm{t}(14 ; 8)(\mathrm{C} 1 ; \mathrm{A} 1) x 2, \operatorname{der}(18) \mathrm{t}(18 ; 12)(\mathrm{D} ; \mathrm{E}),-18$ 


\section{WR21}
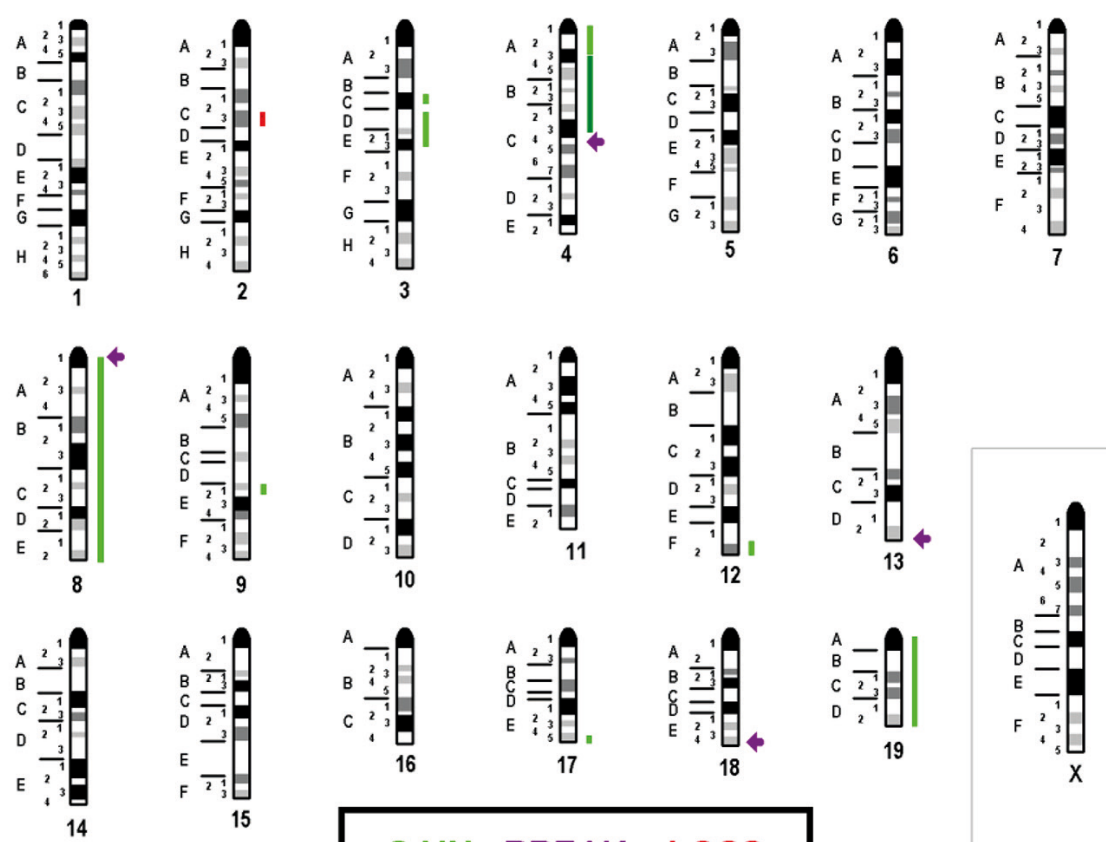

\section{genome}

GAIN BREAK LOSS
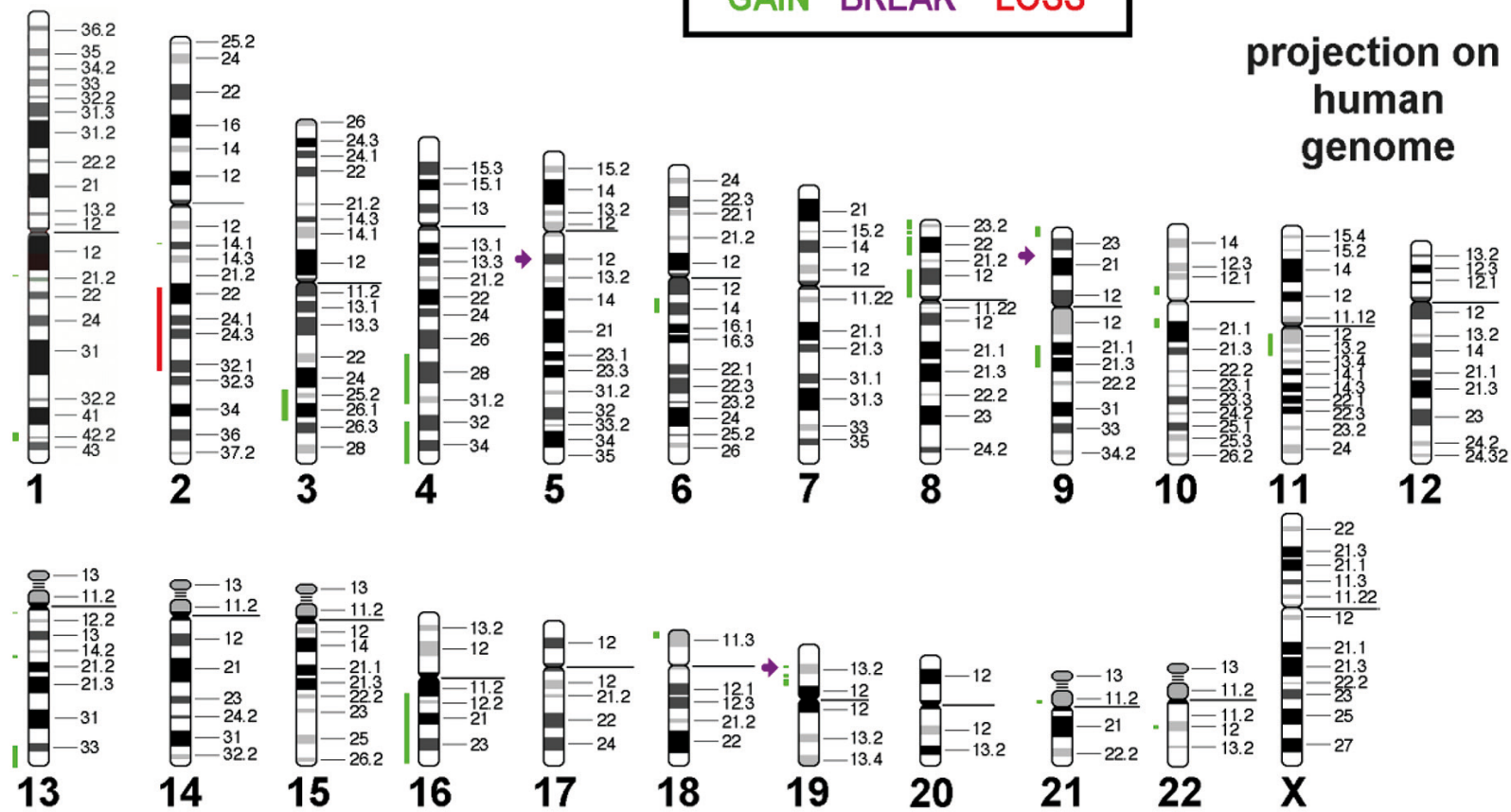

projection on

human

genome

Fig. 3. Imbalances present in WR21 are summarized with respect to a diploid basic karyotype. Gains are depicted as green bars, losses as red bars. In upper part the results are shown for the murine karyotype and in the lower part the translation to human genome. The dark green labeled region of gain at murine chromosome 4 was not detected in aCGH and also not translated to human karyotype.

Most data from the mFISH and mcb for the WR21 and SCA-9 (Table 1) agreed with the aCGH data; the results are shown in Figs. 3 and 4. Some small deletions in murine chromosome 2 and gains in murine chromosomes 3 and 4 (here $4 \mathrm{~A} 4$ to $4 \mathrm{C} 4$, clearly visible $\mathrm{mcb}$ ) were missed in aCGH. These results were translated to the human genome in the same figures. For this study, imbalances larger than 3.5 megabase pairs were included in the evaluation.
According to the corresponding homologous regions in the human karyotype, we compared the results for both cell lines (Table 1 and 2) with the imbalances for four (adenoid cystic carcinoma, myoepitheliomas, pleomorphic adenoma and mucoepidermoid) of the most common types of SGCs. The highest concordance was found with SGCs of myoepitheliomas and mucoepidermoid for WR21, and of mucoepidermoid for SCA-9. 


\section{SCA-9}
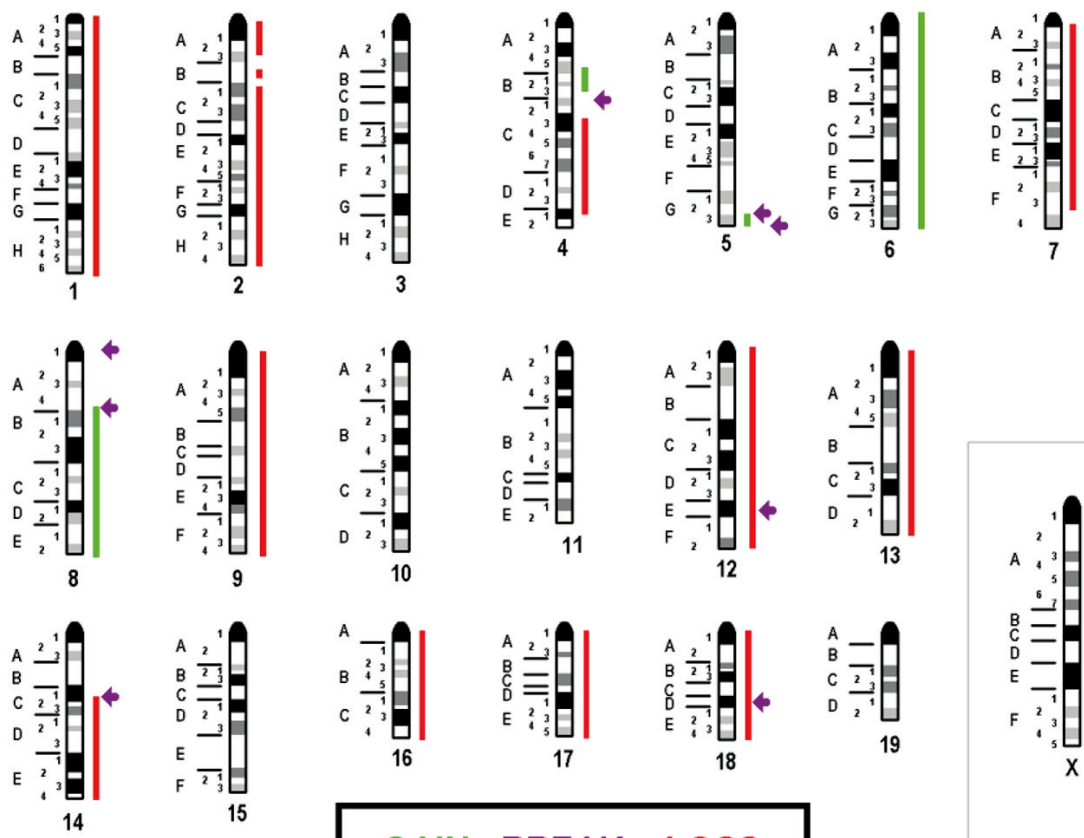

\section{genome}
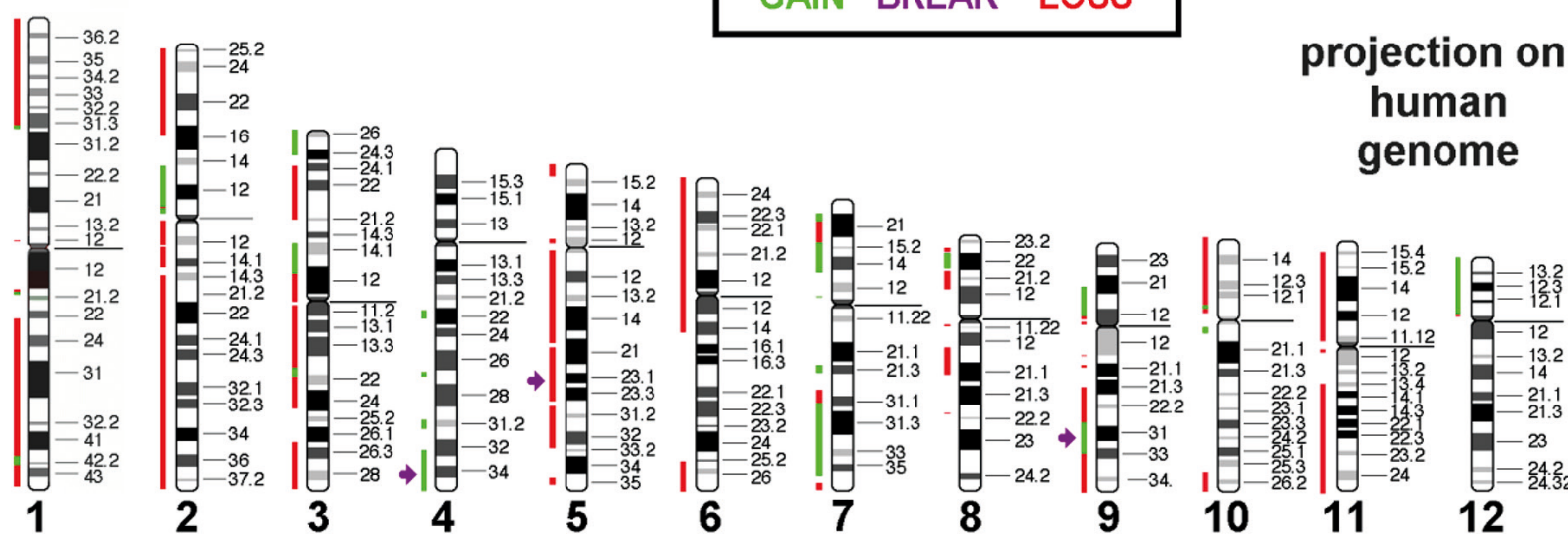

\section{projection on \\ human genome}

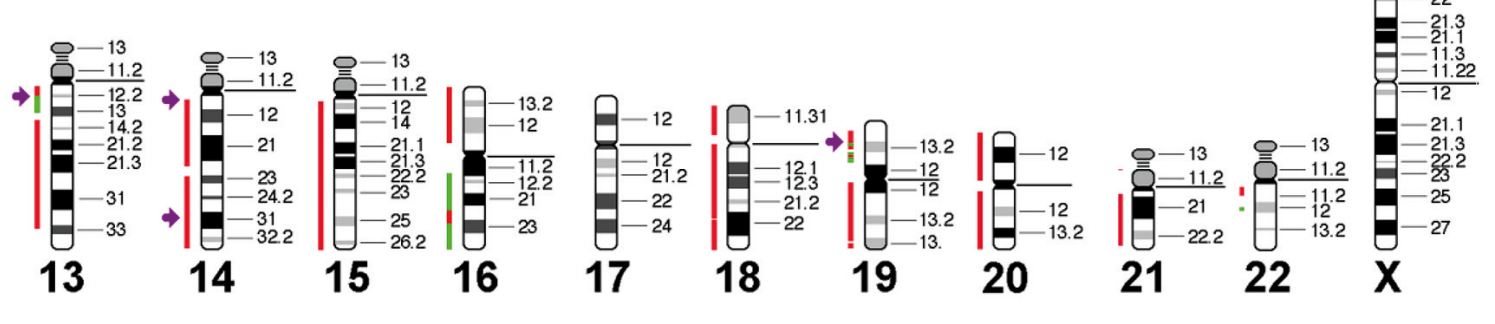

Fig. 4. Imbalances present in SCA 9 are summarized with respect to a tetraploid basic karyotype. Remainder figure as described in legend for Fig. 3.

\section{Discussion}

Both the low incidence and heterogeneity of pathology in SGCs explain why this tumor is one of the least studied human cancer types (Seethala, 2017). SGCs present a diverse range of histological and clinical characteristics (Sood et al., 2018). In the literature, there is also significant heterogeneity in the aberrant genetic and molecular pathways described contributing to the development of SGCs (Müller, 2013; Yin and Ha, 2016).
The two murine tumor cell lines which we examined, commercially available as model systems for SGCs, were successfully studied using molecular cytogenetics (mFISH, $\mathrm{mcb}$ and aCGH) to provide a comprehensive cytogenetic description regarding ploidy, numerical and structural aberrations and tumor-associated breakpoints, as previously done for other murine tumor cell lines (Leibiger et al., 2013; Kubicova et al., 2017; Guja et al., 2017; Rhode et al., 2018).

In our results, clonal changes with few aberrations from the main clone were observed in both cell lines, 
even though two small subclones (denominated as 1 and 2a) were characterizable in WR21 besides one mainline (clone 2). As these cell lines were not karyotyped at the time of establishing, nothing can be stated about karyotypic evolution since then. Considering our own previous studies in other, several decades-old cell lines with known original chromosomal content (Leibiger et al., 2013; Kubicova et al., 2017; Guja et al., 2017; Rhode et al., 2018), all of those were surprisingly stable compared to the original description of the chromosome sets.

Overall, WR21 showed clearly a less aberrant karyotype than SCA-9. Compared to most other solid epithelial tumors, SGCs often were correlated with a normal karyotype or small numbers of chromosomal aberrations (Martins et al., 1995; El Naggar et al., 1997; Hungermann et al., 2002; Vekony et al., 2009), and as expected, salvia carcinomas displayed more chromosomal events than benign tumors from this tissue (Vekony et al., 2009). Thus, WR21 may represent a benign or less advanced cell line than SCA-9. This view is also supported by the fact that polyploidization, i.e. a basic tetraploid karyotype, was observed only in SCA-9, while WR21 was diploid with a gain of only three (derivative) chromosomes. This could be related to telomere-driven tetraploidization in the context of tumor progression (Davoli and de Lange, 2012), but could also be just a cell culture effect (Mastromonaco et al., 2006).

Gains of copy number were observed in both studied cell lines; while gains were more frequent than loss for WR21, the data interpretation used for SCA-9 seems to show a loss rather than a gain of copy numbers. However, this is due to the fact that SCA-9 was interpreted as basically tetraploid - so the high frequency of losses as given in Fig. 4 must consider that this cell line has a massive gain of copy numbers along the entire genome, and the summary in Fig. 4 rather highlights the genomic instability of this cell line.

According to the characterization of WR21 and SCA-9, neither cell line is a model for adenoid cystic carcinomas or pleomorphic adenomas, but most likely for mucoepidermoid SGCs (SCA-9, WR21) and/or myoepitheliomas (WR21 - see Tabs. 1-2).

Interestingly, the breakpoint 13D2 observed in WR21 comprises the gene FGF10 (see suppl. Tab. 1), which has been associated with salivary gland development (Krejci et al., 2009) and breast cancer (Itoh and Ohta, 2014). Maybe this is a hint that this gene also plays a role in SGCs. For SCA- 9 similarly a breakpoint in 8 A1 could be associated with the gene ELAVL1, also called HUR, being described as playing a role in salvia metabolism (Palanisamy et al., 2008) and mucoepidermoid SGC (Cho et al., 2007). The latter confirms that SCA-9 is a model for advanced mucoepidermoid SGC. Another breakpoint (12E) including gene SEL1 plays a role in the salivary glands of Sjögren's syndrome patients (Barrera et al., 2016).
In conclusion, the present study narrowed down the subtypes of two long established murine cancer cell lines to SGCs of mucoepidermoid (SCA-9, WR21) and/ or myoepithelioma (WR21) subtypes and identified three oncogenes potentially playing a role in SGC development. FGF10, ELAVL1/HUR and SEL1 should be further studied with special attention in SGCs. The chromosomal content of the cells should certainly be controlled before doing extensive further studies, to exclude studying subclones with potentially different and/ or advanced karyotypic evolution.

\section{References}

Barrera, M.J., Aguilera, S., Castro, I., Cortés, J., Bahamondes, V., Quest, A. F. G., Molina, C., González, S., Hermoso, M., Urzúa, U., Leyton, C. and González, M. J. 2016. Pro-inflammatory cytokines enhance ERAD and ATF6a pathway activity in salivary glands of Sjögren's syndrome patients. J Autoimmun 75(1):68-81. https://doi. org/10.1016/j.jaut.2016.07.006

Barka, T. 1980. Biologically active polypeptides in submandibular glands, J Histochem Cytochem 28(8):836-859. https:// doi.org/10.1177/28.8.7003006

Barka, T., Gresik, E. S. and Miyazaki, Y. 2005. Differentiation of a mouse submandibular gland-derived cell line (SCA) grown on matrigel. Exp Cell Res 308(2):394-406. https:// doi.org/10.1016/j.yexcr.2005.04.025

Cao, Y., Liu, H., Gao, L., Lu, L., Du, L., Bai, H., Li, J., Said, S., Wang, X., Song, J., Serkova, N., Wei, M., Xiao, J. and Lu, S. 2018. Cooperation between pten and smad4 in murine salivary gland tumor formation and progression. Neoplasia 20:764-774. https://doi.org/10.1016/j. neo.2018.05.009

Cho, N.P., Han, H. S., Soh, Y. and Son, H.J. 2007. Overexpression of cyclooxygenase-2 correlates with cytoplasmic HuR expression in salivary mucoepidermoid carcinoma but not in pleomorphic adenoma. J Oral Pathol Med 36(5):297-203. https://doi.org/10.1111/j.16000714.2007.00526.x

Davoli, T. and de Lange, T. 2012. Telomere-driven tetraploidization occurs in human cells undergoing crisis and promotes transformation of mouse cells. Cancer Cell 21(6):765-776. https://doi.org/10.1016/j.ccr.2012.03.044

El-Naggar, A.K., Dinh, M., Tucker, S. L., Gillenwater, A., Luna, M. A. and Batsakis, J.G. 1997. Chromosomal and DNA ploidy characterization of salivary gland neoplasms by combined FISH and flow cytometry. Hum Pathol 28(8):881-886. https://doi.org/10.1016/S00468177(97)90001-0

Español, A., Dasso, M., Cella, M., Goren, N. and Sales, M. E. 2012. Muscarinic regulation of SCA-9 cell proliferation via nitric oxide synthases, arginases and cyclooxygenases. Role of the nuclear translocation factor-kB. Eur J Pharmacol 683(1-3):43-53. https://doi.org/10.1016/j. ejphar.2012.03.013

Fowler, M. H., Fowler, J., Ducatman, B., Barnes, L. and Hunt, J. L. 2006. Malignant mixed tumors of the salivary gland: a study of loss of heterozygosity in tumor suppressor genes. Mod Pathol 19(3):350-355. https://doi. org/10.1038/modpathol.3800533

Guja, K., Liehr, T., Rincic, M., Kosyakova, N. and Hussein Azawi, S. S. 2017. Molecular cytogenetic characterization identified the murine B-cell lymphoma cell line A-20 as a model for sporadic Burkitt's lymphoma. 
J Histochem Cytochem 65(11):669-677. https://doi. org/10.1369/0022155417731319

Hungermann, D., Roeser, K., Buerger, H., Jakel, T., Loening, T. and Herbst, H. 2002. Relative paucity of gross genetic alterations in myoepitheliomas and myoepithelial carcinomas of salivary glands. J Pathol 198(4):487-494. https:// doi.org/10.1002/path.1234

Itoh, N. and Ohta, H. 2014. Fgf10: a paracrine-signaling molecule in development, disease, and regenerative medicine. Curr Mol Med 14(4):504-509. https://doi.org/10.217 4/1566524014666140414204829

Jee, K.J., Persson, M., Heikinheimo, K., Passador-Santos, F., Aro, K., Knuutila, S., Odell, E. W., Mäkitie, A., Sundelin, K., Stenman, G. and Leivo, I. 2013. Genomic profiles and CRTC1-MAML2 fusion distinguish different subtypes of mucoepidermoid carcinoma. Mod Pathol 26(2):213-222. https://doi.org/10.1038/modpathol.2012.154

Keller, G., Steinmann, D., Quaas, A., Grünwald, V., Janssen, S. and Hussein, K. 2017. New concepts of personalized therapy in salivary gland carcinomas. Oral Oncol 68(1):103113. https://doi.org/10.1016/j.oraloncology.2017.02.018

Krejci, P., Prochazkova, J., Bryja, V., Kozubik, A. and Wilcox, W. R. 2009. Molecular pathology of the fibroblast growth factor family. Hum Mutat 30(9):1245-1255. https://doi.org/10.1002/humu.21067

Kubicova, E., Trifonov, V., Borovecki, F., Liehr, T., Rincic, M., Kosyakova, N. and Hussein, S. S. 2017. First molecular cytogenetic characterization of murine malignant mesothelioma cell line AE17 and in silico translation to the human genome. Curr Bioinform 12(1):11-18. https://doi. org/10.2174/1574893611666160606164459

Leibiger, C., Kosyakova, N., Mkrtchyan, H., Glei, M., Trifonov, V. and Liehr, T. 2013. First molecular cytogenetic high resolution characterization of the NIH $3 \mathrm{~T} 3$ cell line by murine multicolor banding. J Histochem Cytochem 61(4):306-312. https://doi.org/10.1369/0022155413476868

Liehr, T., Starke, H., Heller, A., Kosyakova, N., Mrasek, K., Gross, M., Karst, C., Glaser, M., Fickelscher, I., Kuechler, A., Trifonov, V., Romanenko, S. A. and Weise, A. 2006. Multicolor fluorescence in situ hybridization (FISH) applied to FISH-banding. Cytogenet Genome Res 114(34):240-244. https://doi.org/10.1159/000094207

Mastromonaco, G.F., Perrault, S.D., Betts, D.H. and King, W. A. 2006. Role of chromosome stability and telomere length in the production of viable cell lines for somatic cell nuclear transfer. BMC Dev Biol 6(1):41. https:// doi.org/10.1186/1471-213X-6-41

Martins, C., Fonseca, I., Felix, A., Roque, L. and Soares, J. 1995. Benign salivary gland tumors: A cytogenetic study of 21 cases. J Surg Oncol 60(4):232-237. https://doi. org/10.1002/jso.2930600404

Matse J.H., Veerman E.C.I., Bolscher J.G. M., René Leemans C., Ylstra B. and Bloemena E. 2017. High number of chromosomal copy number aberrations inversely relates to $\mathrm{t}(11 ; 19)(\mathrm{q} 21 ; \mathrm{p} 13)$ translocation status in mucoepidermoid carcinoma of the salivary glands. Oncotarget 8(41): 69456-69464. https://doi.org/10.18632/oncotarget.17282

Murase, R., Sumida, T., Kawamura, R., Onishi-Ishikawa, A. Hamakawa, H., McAllister, S. D. and Desprez, P. 2016. Suppression of invasion and metastasis in aggressive salivary cancer cells through targeted inhibition of ID1 gene expression. Cancer Lett 377(1):11-16. https://doi. org/10.1016/j.canlet.2016.04.021

Müller, S. 2013. An update on salivary gland pathology. Head Neck Pathol 7 (Suppl 1):S1-S2. https://doi.org/10.1007/ s12105-013-0463-y
Nielsen, L. L., Gurnani, M., Porter, G., Trexler, S., Emerson, D. and Tyler, R. D. 1994. Development of a nude mouse model of ras-mediated neoplasia using WR21 cells from a transgenic mouse salivary tumor. In Vivo 8(3):295-302.

Omitola, O. G. and lyogun, C. A. 2018. Immunohistochemical study of salivary gland tumors in a tertiary institution in South-South Region of Nigeria. J Oral Maxillofac Pathol 22(2):163-167. https://doi.org/10.4103/jomfp. JOMFP_108_17

Palanisamy, V., Park, N.J., Wang, J. and Wong, D. T. 2008. AUF1 and HuR proteins stabilize interleukin-8 mRNA in human saliva. J Dent Res 87(8):772-776. https://doi. org/10.1177/154405910808700803

Persson, F., Andrén, Y., Winnes, M., Wedell, B., Nordkvist, A., Gudnadottir, G., Dahlenfors, R., Sjögren, H., Mark, J. and Stenman, G. 2009. High-resolution genomic profiling of adenomas and carcinomas of the salivary glands reveals amplification, rearrangement, and fusion of HMGA2. Genes Chromosomes Cancer 48(1):69-82. https://doi. org/10.1002/gcc.20619

Rao, P.H., Roberts, D., Zhao, Y., Bell, D., Harris, C.P., Weber, R. S. and El-Naggar, A. K. 2008. Deletion of 1p32-p36 is the most frequent genetic change and poor prognostic marker in adenoid cystic carcinoma of the salivary glands. Clin Cancer Res 14(16):5181-5187. https://doi. org/10.1158/1078-0432.CCR-08-0158

Rhode, H., Liehr, T., Kosyakova, N., Rincic, M. and Azawi, S. S. H. 2018. Molecular cytogenetic characterization of two murine colorectal cancer cell lines. OBM Genetics 2(3). https://doi.org/10.21926/obm.genet.1803037

Seethala, R. R. 2017. Salivary gland tumors: current concepts and controversies. Surg Pathol Clin 10(1):155-176. https://doi.org/10.1016/j.path.2016.11.004

Solanki, G. 2011. Tumors of salivary glands. IJPR 1(2):35-38. https://doi.org/10.7439/ijpr.v1i2.355

Sood, S., McGurk, M. and Vaz, F. 2016. Management of salivary gland tumours: United Kingdom national multidisciplinary guidelines. J Laryngol Otol 130(S2):S142-S149. https://doi.org/10.1017/S0022215116000566

Trzaskawka, E., Vigo, J., Egea, J.-C., Goldsmith, M.-C., Salmon, J.-M., Deville and De Periere, D. 2000. Cultured tumor cells of murine submandibular gland origin: a model to investigate $\mathrm{pHi}$ regulation of salivary cells. Eur J Oral Sci 108(1):54-58. https://doi.org/10.1034/j.16000722.2000.00670.x

Vekony, H., Röser, K., Löning, T., Ylstra, B., Meijer, G. A., van Wieringen, W. N., van de Wiel, M. A., Carvalho, B., Kok, K., Leemans, S. R., van der Waal, I. and Bloemena, E. 2009. Copy number gain at 8q12.1-q22.1 is associated with a malignant tumor phenotype in salivary gland myoepitheliomas. Genes Chromosomes Cancer 48(2):202-212. https://doi.org/10.1002/gcc.20631

Yin, L. X. and Ha, P. K. 2016. Genetic alterations in salivary gland cancers. Cancer 122(12):1822-1831. https://doi. org/10.1002/cncr.29890

Young, L. F. and Martin, K. R. 2006. Time-dependent resveratrol-mediated mRNA and protein expression associated with cell cycle in WR-21 cells containing mutated human c-Ha-Ras. Mol Nutr Food Res 50(1):70-77. https://doi. org/10.1002/mnfr.200500149

Zboray, K., Mohrherr, J., Stiedl, P., Pranz, K., Wandruszka, L., Grabner, B., Eferl, R., Moriggl, R., Stoiber, D., Sakamoto, K., Wagner, K., Popper, H., Casanova, E. and Moll, H. 2018. AKT3 drives adenoid cystic carcinoma development in salivary glands. Cancer Med 7(2):445-453. https://doi.org/10.1002/cam4.1293 
Supplement 1. Translation of murine to human data for WR21

\begin{tabular}{|c|c|c|c|}
\hline \multirow{2}{*}{ region } & \multirow{2}{*}{ gain } & \multicolumn{2}{|c|}{ homologue region in human } \\
\hline & & cytoband & position (GRCh37/hg19) \\
\hline 3D-E3 & $\mathrm{X} 1$ & $3 q 25.1-q 26.2$ & 3:149055816-167822106 \\
\hline $3 C$ & $\mathrm{X} 1$ & $4 q 27-q 31.1$ & 4:122242382-141190230 \\
\hline $8 A 1-E 2$ & $\mathrm{X} 1$ & $\begin{array}{c}19 p 13.2 \\
\text { 13q33.1-q34 } \\
8 p 23.3-p 23.2 \\
8 p 23.2-p 23.1 \\
\text { gap } \\
13 q 14.3 \\
8 p 11.23-p 11.21 \\
8 p 11.21 \\
8 p 12 \\
8 p 23.1 \\
8 p 23.1-p 22 \\
4 q 32.2-q 35.2 \\
8 p 22-p 21.3 \\
19 p 13.12-p 13.11 \\
22 q 12.3 \\
4 q 31.1-q 31.23 \\
19 p 13.2-p 13.12 \\
16 q 11.2-q 22.1 \\
16 q 22.1-q 24.3 \\
1 q 42.13-q 42.3 \\
10 p 11.22-p 11.21\end{array}$ & $\begin{array}{c}19: 7112183-8071013 \\
13: 103533915-115092930 \\
8: 591286-5358752 \\
8: 5368147-6693649 \\
\\
13: 52435459-53211718 \\
8: 36716542-42505949 \\
8: 42691750-43058925 \\
8: 29190466-36677574 \\
8: 8108776-9640417 \\
8: 12579073-17958954 \\
4: 163504024-190884657 \\
8: 18227877-20177976 \\
19: 16163040-19774937 \\
22: 33658332-35953121 \\
4: 141251922-150892329 \\
19: 12745060-14683008 \\
16: 46693273-69976105 \\
16: 70109527-90110030 \\
1: 229404294-235324774 \\
10: 33112469-35152269\end{array}$ \\
\hline 9E1-E2 & $\mathrm{X} 1$ & $6 q 13-q 14.3$ & $6: 74104388-86360515$ \\
\hline $12 \mathrm{~F} 1-\mathrm{F} 2$ & $\mathrm{X} 1$ & No discerption (Gap) & No discerption (Gap) \\
\hline $19 A-D$ & $\mathrm{X} 1$ & $\begin{array}{c}11 q 12.1-q 13.3 \\
9 q 21.11-q 21.31 \\
2 q 13 \\
9 p 24.3-p 24.1 \\
10 q 11.23-q 21.1\end{array}$ & $\begin{array}{c}11: 57844834-68709722 \\
9: 69086307-82777364 \\
2: 114171139-114321953 \\
9: 51374-6659223 \\
10: 51917603-54540082\end{array}$ \\
\hline 17E5 & $\mathrm{X} 1$ & $18 p 11.32$ & $18: 861722-2534400$ \\
\hline \multirow{2}{*}{ region } & \multirow{2}{*}{ loss } & \multicolumn{2}{|c|}{ homologue region in human } \\
\hline & & cytoband & position (GRCh37/hg19) \\
\hline $2 \mathrm{C3}$ & $\mathrm{X} 1$ & $2 q 22.1-q 32.1$ & 2:139292421-187530602 \\
\hline \multirow[t]{2}{*}{ region } & breakpoint & \multicolumn{2}{|c|}{ homologue region in human } \\
\hline & & cytoband & potential tumor associated genes \\
\hline $4 C 4$ & inv. & 9p22.3 22.2 & PSIP1 \\
\hline $8 \mathrm{~A} 1$ & $\mathrm{t}$ & 19p13.2 & ADGRE4P \\
\hline 13D2 & add & $5 p 12$ & FGF10 \\
\hline
\end{tabular}


Supplement 2. Translation of murine to human data for SCA-9

\begin{tabular}{|c|c|c|c|}
\hline \multirow{2}{*}{ region } & \multirow{2}{*}{ gain } & \multicolumn{2}{|c|}{ homologue region in human } \\
\hline & & cytoband & position (GRCh37/hg19) \\
\hline 4A5-B3 & $\mathrm{X} 1$ & $\begin{array}{l}9 q 22.33-q 33.2 \\
9 p 13.1-p 21.2\end{array}$ & $\begin{array}{c}\text { 9:100037894-123488942 } \\
\text { 9:27325073-38472099 }\end{array}$ \\
\hline $5 G 2-G 3$ & $\mathrm{X} 2$ & $\begin{array}{c}13 q 12.13-q 13.2 \\
7 q 21.1-q 21.3\end{array}$ & $\begin{array}{c}13: 26784894-34260463 \\
7: 97598308-99229367\end{array}$ \\
\hline 6A1-qter & $\mathrm{x} 1$ & $\begin{array}{c}\text { 7p21.3-p22.1 } \\
7 q 21.2-q 21.3 \\
12 p 11.21 \\
12 p 11.21 \\
12 p 11.22-p 13.31 \\
12 p 13.31-p 13.33 \\
12 p 13.31 \\
12 p 13.33 \\
10 q 11.21-q 11.22 \\
4 q 27 \\
4 q 22.1-q 22.3 \\
3 p 25.2-p t r \\
3 p 12.3-p 14.1 \\
3 q 21.3 \\
3 p 25.1-p 25.2 \\
3 q 21.3-q 22.1 \\
2 p 11.2-p 13.3 \\
2 p 11.2 \\
1 p 31.1 \\
7 p 14.3-p 15.3 \\
7 q 31.1-q 36.1 \\
7 q 36.1 \\
22 q 11.11-q 11.21\end{array}$ & $\begin{array}{c}7: 7132996-12536829 \\
7: 92745197-97502117 \\
12: 30985917-31165338 \\
12: 31424829-32537434 \\
12: 9901365-30943693 \\
12: 2903120-7695890 \\
12: 8071763-9214464 \\
12: 66113-2823666 \\
10: 43277986-46218167 \\
4: 121018693-122194687 \\
4: 89178698-95273100 \\
3: 61304-12897767 \\
3: 64017713-75322601 \\
3: 125725101-129038484 \\
3: 12939278-15163105 \\
3: 129094932-129632650 \\
2: 68715037-87095119 \\
2: 88302422-89174373 \\
1: 67631910-68317098 \\
7: 23254035-33103246 \\
7: 112138919-149583263 \\
7: 150032467-150558657 \\
22: 17565811-18659740\end{array}$ \\
\hline $8 \mathrm{~A} 4-\mathrm{E} 2$ & $\mathrm{X} 1$ & $\begin{array}{c}4 q 32.2-q t r \\
4 q 31.1-q 31.23 \\
16 q 22.1-q 24.3 \\
16 q 11.2-q 22.1 \\
1 q 42.13-q 42.3 \\
10 q 11.21-q 11.22 \\
19 p 13.11-p 13.12 \\
19 p 13.12-p 13.2 \\
22 q 12.3 \\
8 p 22-23.1\end{array}$ & $\begin{array}{c}4: 163504024-190884657 \\
4: 141251922-150892329 \\
16: 70109527-90110030 \\
16: 46693273-69976105 \\
1: 229404294-235324774 \\
10: 33112469-35152269 \\
19: 16163040-19774937 \\
19: 12745060-14683008 \\
22: 33658332-35953121 \\
8: 12579073-17958954\end{array}$ \\
\hline \multirow{2}{*}{ region } & \multirow{2}{*}{ loss } & \multicolumn{2}{|c|}{ homologue region in human } \\
\hline & & cytoband & position (GRCh37/hg19) \\
\hline $1 \mathrm{~A} 2-\mathrm{H} 6$ & $\mathrm{x} 1$ & $\begin{array}{c}8 q 11.21-q 12.1 \\
8 q 13.1-q 21.11 \\
6 p 12.3-p 12.2 \\
6 q 11-q 13 \\
6 p 12.1-p 11.2 \\
2 q 14.3-q 21.1 \\
2 q 11.2-q 12.2 \\
13 q 33.1 \\
2 q 32.1-q 32.2 \\
2 q 32.2-q 37.3 \\
5 q 21.1 \\
18 q 21.32-q 22.1 \\
2 q 14.3 \\
2 q 14.1-q 14.3 \\
2 q 21.2-q 22.1 \\
1 q 32.1-q 32.2 \\
1 q 21.1 \\
1 p 11.2 \\
1 q 23.1-q 32.1 \\
Y q 11.23 \\
1 q 43-q 44 \\
4 q 26 \\
1 q 32.2-q 42.13\end{array}$ & $\begin{array}{c}8: 50767106-56535248 \\
8: 67336477-76107163 \\
6: 49796129-52568703 \\
6: 61967179-73920868 \\
6: 56223874-58686221 \\
2: 128848553-131914911 \\
2: 97151065-106819719 \\
13: 103237605-103533914 \\
2: 189007277-190504466 \\
2: 190506076-242812118 \\
5: 98439740-102728411 \\
18: 58351903-65328593 \\
2: 122585948-126347698 \\
2: 114436107-122578025 \\
2: 133138389-138607743 \\
1: 206075775-207534964 \\
1: 143881371-144095755 \\
1: 120754434-120887322 \\
1: 158516903-205922697 \\
Y: 28358518-28544030 \\
1: 240253393-247125743 \\
4: 119339188-119512723 \\
1: 207575939-227644727\end{array}$ \\
\hline
\end{tabular}




\begin{tabular}{|c|c|c|c|}
\hline $2 \mathrm{~A} 1-\mathrm{A} 3$ & $\mathrm{X} 1$ & $10 q 12.1-q 15$ & 10:5915452-27157072 \\
\hline $2 \mathrm{~B}$ & $x 4$ & $2 q 22.1-q 32.1$ & 2:140065297-188395329 \\
\hline $2 \mathrm{C} 1-\mathrm{H} 4$ & $\mathrm{X} 1$ & $\begin{array}{c}20 p 13-p 11.21 \\
20 p 13 \\
20 q 11.21-q 13.32 \\
20 q 13.32-q 13.33 \\
15 q 13.3-q 21.2 \\
11 q 12.1 \\
11 q 11 \\
11 p 11.12 \\
11 p 14.2-p 11.2 \\
2 q 11.1-q 11.2 \\
2 q 13 \\
2 p 11.2 \\
2 q 13\end{array}$ & $\begin{array}{c}20: 1736101-25606620 \\
20: 102147-1447942 \\
20: 29933153-58056214 \\
20: 58148222-62907435 \\
15: 32906987-51298173 \\
11: 56082416-57753858 \\
11: 55080583-55323018 \\
11: 51377850-51539057 \\
11: 26296397-48658712 \\
2: 95642277-97040617 \\
2: 111483204-112960231 \\
2: 87345633-87996071 \\
2: 112973390-113650007\end{array}$ \\
\hline $4 C 5-E 1$ & $\mathrm{X} 1$ & $\begin{array}{c}1 \mathrm{p} 32.1-\mathrm{p} 31.3 \\
1 \mathrm{p} 36.33-\mathrm{p} 32.2 \sim 1\end{array}$ & $\begin{array}{c}1: 59120351-67562260 \\
1: 894315-59012766\end{array}$ \\
\hline 7A1-F3 & $\mathrm{X} 1$ & $\begin{array}{c}19 q 13.42-q 13.43 \\
19 q 13.43 \\
19 q 13.31-q 13.33 \\
19 q 12-q 13.31 \\
19 q 12 \\
19 q 13.33-q 13.41 \\
16 p 13.11 \\
11 p 15.1-p 14.3 \\
15 q 11.2 \\
15 q 11.2-q 13.1 \\
15 q 13.1-q 13.3 \\
15 q 26.3 \\
15 q 26.1-q 26.3 \\
15 q 25.3-q 26.1 \\
15 q 25.1-q 25.3 \\
11 p 11.12 \\
11 q 13.4-q 14.3 \\
10 p 11.21 \\
11 p 15.4-p 15.1 \\
16 p 13.11 \\
16 p 13.11-p 12.3 \\
16 p 12.3-p 12.2 \\
16 p 12.2-p 11.2 \\
16 p 11.2 \\
16 p 11.2\end{array}$ & $\begin{array}{c}19: 54368915-57485284 \\
19: 58523795-59089552 \\
19: 45010010-48707700 \\
19: 30093064-44860951 \\
19: 28589680-30085362 \\
19: 48800017-51921957 \\
16: 16252815-16388674 \\
11: 17403485-25251145 \\
15: 22833222-23086601 \\
15: 23914751-28586067 \\
15: 29107424-32578594 \\
15: 99080385-102265870 \\
15: 91593058-99078056 \\
15: 85829657-91565912 \\
15: 80253398-85682414 \\
11: 49250334-49827246 \\
11: 71627032-89350901 \\
10: 37191655-37402201 \\
11: 3631069-17360027 \\
16: 15260325-15369270 \\
16: 16681590-18325190 \\
16: 18608156-21351663 \\
16: 21572755-28339524 \\
16: 28390845-29030948 \\
16: 29661006-31520748\end{array}$ \\
\hline 9A1-F4 & & $\begin{array}{c}11 q 14.3-q 22.3 \\
19 p 13.2 \\
7 p 14.3-p 14.2 \\
11 q 22.3-q 25 \\
15 q 21.2 \\
15 q 21.2-q 25.1 \\
6 p 12.2-p 12.1 \\
6 q 13-q 14.3 \\
15 q 25.1 \\
3 q 22.3-q 24 \\
3 q 22.1-q 22.3 \\
3 p 21.31-p 21.1 \\
3 p 24.1-p 22.2 \\
3 p 22.2-p 21.31\end{array}$ & $\begin{array}{c}11: 89860533-107436639 \\
19: 8919008-11689880 \\
7: 33134362-36494039 \\
11: 107452617-134843539 \\
15: 51349622-51942502 \\
15: 51961808-78956872 \\
6: 52656530-55784577 \\
6: 74104388-86360515 \\
15: 79042978-80196839 \\
3: 138372654-148087492 \\
3: 129931635-138353358 \\
3: 46446256-52346387 \\
3: 27753690-37261140 \\
3: 37269243-46423369\end{array}$ \\
\hline $12 \mathrm{~A} 1-\mathrm{E}$ & $\mathrm{x} 2$ & $\begin{array}{c}2 p 25.1-p 23.3 \\
2 p 25.1 \\
2 p 25.1 \\
2 p 25.3-p 25.1 \\
7 q 22.3-q 31.1 \\
7 p 21.3-p 21.1 \\
7 q 31.1 \\
14 q 12-q 22.1\end{array}$ & $\begin{array}{c}2: 10303009-26361943 \\
2: 9354723-9994801 \\
2: 9996101-10284917 \\
2: 140908-9278318 \\
7: 105210238-107772185 \\
7: 12561752-19748810 \\
7: 107772206-112136146 \\
14: 25157192-52251174\end{array}$ \\
\hline $12 \mathrm{E}-\mathrm{F} 1$ & $\mathrm{X} 1$ & $14 q 23.1-q 32.33$ & 14:58666612-106375879 \\
\hline 12F1-F2 & $\mathrm{X} 2$ & $\begin{array}{c}7 q 36.3 \\
7 p 21.1-p 15.3\end{array}$ & $\begin{array}{c}\text { 7:157225645-158937901 } \\
7: 19761201-22528893\end{array}$ \\
\hline
\end{tabular}




\begin{tabular}{|c|c|c|c|}
\hline 13A1-qter & $\mathrm{X} 1$ & $\begin{array}{c}\text { 10p15.3-p15.1 } \\
1 q 42.3-q 43 \\
7 p 14.2-p 13 \\
6 p 22.3-p 22.1 \\
6 p 25.3-p 23 \\
6 p 23-p 22.3 \\
9 q 22.1-q 22.32 \\
5 q 35.2-q 35.3 \\
5 q 31.1-q 31.2 \\
9 q 21.32-q 21.33 \\
9 q 22.32-q 22.33 \\
9 p 13.1 \\
9 q 12-q 13 \\
9 p 11.2 \\
8 q 22.1 \\
5 p 15.33-p 15.31 \\
5 q 14.3-q 15 \\
5 q 13.2-q 14.3 \\
5 q 11.1-q 13.2 \\
1 p 11.2 \\
5 p 12\end{array}$ & $\begin{array}{c}10: 138698-5865622 \\
1: 235330060-240084659 \\
7: 36524506-43605930 \\
6: 20065223-28502803 \\
6: 181261-15099150 \\
6: 15104709-20060798 \\
9: 91031851-97067712 \\
5: 173750964-177039611 \\
5: 134073478-137090938 \\
9: 86231955-90340399 \\
9: 97320957-99417669 \\
9: 38810965-40707569 \\
9: 65585614-65901647 \\
9: 43623473-43941731 \\
8: 97247028-97373828 \\
5: 191425-7935441 \\
5: 84566270-96144383 \\
5: 70265557-84371909 \\
5: 49569996-68922426 \\
1: 121149401-121350677 \\
5: 43446298-46118514\end{array}$ \\
\hline 14C1-E5 & $\mathrm{X} 2$ & $\begin{array}{c}14 q 22.1-q 23.1 \\
14 q 11.2-q 12 \\
14 q 12 \\
13 q 12.12 \\
13 q 12.11 \\
13 q 14.2 \\
13 q 12.13 \\
13 q 12.12 \\
13 q 14.2-q 14.3 \\
8 p 23.1 \\
8 p 21.3-p 12 \\
13 q 14.11-q 14.2 \\
13 q 14.3-q 33.1\end{array}$ & $\begin{array}{c}14: 52688635-58629894 \\
14: 20211286-24987352 \\
14: 25040539-25149959 \\
13: 25188452-25511922 \\
13: 20207279-23370461 \\
13: 49821990-50161404 \\
13: 25685086-26668986 \\
13: 23853398-24896355 \\
13: 50192169-52356487 \\
8: 9744629-11737304 \\
8: 20206584-29151199 \\
13: 41469941-49799059 \\
13: 53226033-103089581\end{array}$ \\
\hline 16pter-qter & $\mathrm{X} 1$ & $\begin{array}{c}16 p 13.3-p 13.11 \\
16 p 13.11 \\
8 q 11.21 \\
12 p 11.21 \\
22 q 11.21 \\
3 q 27.1-q 29 \\
3 q 29 \\
3 q 11.1-q 21.2 \\
3 p 12.3-p 11.1 \\
21 q 11.2-q 22.3 \\
21 q 11.2 \\
18 p 11.21 \\
2 q 21.1\end{array}$ & $\begin{array}{c}16: 3283710-15197331 \\
16: 15478874-16187414 \\
8: 48206338-49865275 \\
12: 32634919-33054761 \\
22: 19010381-22338262 \\
3: 182965714-195325931 \\
3: 195428230-197771581 \\
3: 93527487-125343459 \\
3: 75865702-90309600 \\
21: 15515528-43438088 \\
21: 14535253-14714360 \\
18: 15016525-15155234 \\
2: 132604281-132757591\end{array}$ \\
\hline 17A1-E5 & $\mathrm{X} 1$ & $\begin{array}{c}6 q 27 \\
6 q 25.3-q 27 \\
6 q 27 \\
5 q 15-q 21.1 \\
16 p 13.3 \\
5 q 35.1 \\
6 p 21.32-p 21.2 \\
21 q 22.3 \\
19 p 13.12 \\
19 p 13.2 \\
6 p 22.1-p 21.32 \\
6 p 21.2-p 12.3 \\
3 p 25.1-p 24.3 \\
2 q 12.2-q 12.3 \\
19 p 13.3 \\
5 q 21.1-q 22.1 \\
18 p 11.32-p 11.22 \\
2 p 23.2-p 16.3 \\
2 p 16.3-p 16.2 \\
18 p 11.32\end{array}$ & $\begin{array}{c}6: 167120855-167552070 \\
6: 160103032-166797236 \\
6: 167859539-170893754 \\
5: 96202316-98405239 \\
16: 222880-3208490 \\
5: 171946752-172722349 \\
6: 33359177-39058058 \\
21: 43490502-45122943 \\
19: 15270296-15808207 \\
19: 8366687-8811037 \\
6: 29322703-33297218 \\
6: 39266498-49681826 \\
3: 16307846-20231899 \\
2: 107383985-108798215 \\
19: 4229082-6862967 \\
5: 102759315-110063021 \\
18: 2534401-9972541 \\
2: 29033520-51699597 \\
2: 51709987-53282184 \\
18: 861722-2534400\end{array}$ \\
\hline
\end{tabular}




\begin{tabular}{|c|c|c|c|}
\hline 18A1-D3 & $\mathrm{X} 1$ & $\begin{array}{c}10 p 11.21 \\
10 p 12.1-p 11.22 \\
10 p 12.1 \\
10 p 11.21 \\
18 p 11.32 \\
18 q 11.1-q 12.3 \\
2 q 14.3 \\
5 q 22.1-q 22.2 \\
5 q 31.2-q 32 \\
5 q 22.2-q 23.3\end{array}$ & $\begin{array}{c}10: 35284099-35521818 \\
10: 28950711-32678701 \\
10: 27747786-28722506 \\
10: 35676708-37094546 \\
18: 112543-599224 \\
18: 18528605-41073893 \\
2: 127805408-128786667 \\
5: 110280120-112296881 \\
5: 137225085-147624774 \\
5: 112310736-130339352\end{array}$ \\
\hline 18D3-qter & $\mathrm{X} 2$ & $\begin{array}{c}5 q 32-q 33.1 \\
18 p 11.22-p 11.21 \\
18 q 21.31-q 21.32 \\
18 p 11.21 \\
18 q 12.3-q 21.31 \\
18 q 22.1-q 23\end{array}$ & $\begin{array}{c}5: 147647374-150177176 \\
18: 10202644-11518916 \\
18: 54267924-58201586 \\
18: 11649353-13871680 \\
18: 41355914-54244819 \\
18: 66339761-78010601\end{array}$ \\
\hline \multirow{2}{*}{ region } & \multirow{2}{*}{ breakpoint } & \multicolumn{2}{|c|}{ homologue region in human } \\
\hline & & cytoband & potential tumor associated genes \\
\hline $4 C 1$ & del & $9 q 31.3$ & AKAP2/ C9orf84 \\
\hline $5 G 3$ & dup, inv & $7 q 21.3$ & ASNS / BAIAP2L1 \\
\hline $5 \mathrm{G} 2$ & dup & $7 q 21.3$ & ASNS / BAIAP2L1 \\
\hline $8 \mathrm{~A} 1$ & $\mathrm{t}$ & 19p13.2 & ELAVL1 also called HUR / FCER2 \\
\hline $8 \mathrm{~B} 1$ & $\mathrm{t}$ & $4 q 34.2$ & ASB5 \\
\hline $12 \mathrm{E}$ & $\mathrm{t}$ & $14 q 31.1$ & SEL1L / TSHR \\
\hline $14 C 1$ & $\mathrm{t}$ & $14 q 22.2$ & CGRRF1 / CNIH1 / GCH1 / GMFB \\
\hline $18 \mathrm{D}$ & $\mathrm{t}$ & $5 q 23.1$ & LOX / FTMT \\
\hline
\end{tabular}

